\title{
Experimental Study of Degradation Modes and Their Effects on Reliability of Photovoltaic Modules after 12 Years of Field Operation in the Steppe Region
}

\author{
M. SAadsaoud ${ }^{a}$, A.H. Ahmed ${ }^{a}$, Z. ER ${ }^{b, *}$ And Z. Rounbah ${ }^{c}$ \\ ${ }^{a}$ Laboratoire d'Automatique et Signaux de Annaba (LASA), University of Annaba, Algeria \\ ${ }^{b}$ Department of Physics Engineering (13b), Faculty of Science and Letters, \\ Istanbul Technical University, Istanbul, Turkey \\ ${ }^{c}$ Materials and electronic systems laboratory, University of Bordj Bou Arreridj, Algeria
}

\begin{abstract}
This paper presents an evaluation of the performance degradation of photovoltaic modules after twelve operation years in a steppe region environment in Algeria. The objective is to understand the different degradation modes of the photovoltaic modules and associated factors and their impact on the electrical properties $\left(V_{\mathrm{oc}}, I_{\mathrm{sc}}\right.$, $V_{\max }, I_{\max }, P_{\max }$ and FF) using the degradation tests of IEC 61215 qualification standard and the electroluminescence test. The experimental results show that yearly degradation rates of the maximum power output $P_{\text {max }}$ present the highest possible loss, ranging from $2.08 \%$ to $5.2 \%$. Additionally, the results show that the short-circuit current $I_{\mathrm{sc}}$ comes second with yearly degradation rates spanning from $2.75 \%$ to $2.84 \%$. Finally the open-circuit voltage $V_{\text {oc }}$ is the least affected, with yearly degradation occurring from $0.01 \%$ to $4.25 \%$.
\end{abstract}

DOI: $10.12693 /$ APhysPolA.132.930

PACS/topics: 88.40.-J, 88.40.H-, 88.40.FF

\section{Introduction}

The energy needed for technology age is the most important topic. With the developing technology, the rapid increase of world population causes an increase of energy consumption [1]. Photovoltaics (PV) is becoming a mainstream electricity provider and the need for PV cells will spike compared to current demand [2]. The PV module is the main part of a solar PV system because it transforms the solar radiation into electricity. When a product is placed on the market, the manufacturer must ensure that it will maintain its initial specifications over a defined period of use. This period corresponds to the product warranty offered by the manufacturer.

In general, the life of a module is the period during which its performance is guaranteed within a given range. The calculation of the lifetime is a major factor in the field of industry. For a PV system, lifetime is the first factor that has to be studied. When part of a module is damaged, the module stops working and the entire system will be blocked. The lifetime of a PV module can be defined as the period during power production, and can also be defined as a point in time at which the module is no longer acceptable. The current consensus is that a PV module is guaranteed for 25 years at $80 \%$ of its initial power (and $90 \%$ at 10 years) [3]. In order to estimate the lifetime of the product under specific conditions, the mathematical models are used to give the relation between the lifetime and the reliability of the module [4].

*corresponding author; e-mail: erzuh@itu.edu.tr
On the other hand, the reliability of a PV module can be understood in terms of its ability to warrant the amount of energy that modules will produce over its lifetime. The main factors responsible for reducing the lifetime of a PV module are the degradation mechanisms which are dependent on a number of physical and climatic factors. The outcome of degradation is the reduction the amount of energy produced, related with the changes in the electrical characteristics of PV modules, such as $I-V$ and $P-V$ curves, open-circuit voltage $V_{\text {oc }}$, short-circuit current $I_{\mathrm{sc}}$, maximum output current $I_{\mathrm{max}}$, maximum output voltage $V_{\max }$, maximum power output $P_{\max }$, and fill factor (FF) [5, 6]. FF is an important performance indicator, representing the ratio between the maximum power that can be delivered by a cell $P_{\max }$ and the power resulting from the multiplication of $I_{\mathrm{sc}}$ and $V_{\mathrm{oc}}$, under specific irradiance and temperature conditions $[7,8]$. The nomenclature of this study is illustrated in Table I.

TABLE I

Notations, symbols and their meanings.

\begin{tabular}{c|c|c|c}
\hline \hline \multicolumn{4}{c}{ Nomenclature } \\
\hline$V_{\mathrm{Oc}}$ & open-circuit voltage & $I_{\max }$ & max. output current \\
$I_{\mathrm{Sc}}$ & short-circuit current & $V_{\max }$ & max. output voltage \\
$P_{\max }$ & max. power output & $\mathrm{FF}$ & fill factor \\
$\mathrm{EVA}$ & ethylene vinyl acetate & $\mathrm{PV}$ & photovoltaic \\
$\mathrm{RD}$ & parameter degradation rate & $\mathrm{RDt}$ & yearly degradation rate
\end{tabular}

\section{Electrical characteristics of the studied PV module}

In this study, two identical mono crystalline photovoltaic modules Isofoton IS-80-12, consisting of 
36 monocrystalline silicon cells, with a maximum power of $80 \mathrm{~W}$ were used, as well as two bypass diodes, connected in parallel and two sheets of a EVA (ethylene vinyl acetate), which is the copolymer of ethylene and vinyl acetate. It is an extremely elastic material that can be sintered to form a porous material similar to rubber, yet with excellent toughness. Cover glass with a thickness of $3.2 \mathrm{~mm}$, and a water-resistant PV back sheet with aluminum frame were also used in this study. The electrical parameters of the studied modules are shown in Table II.

TABLE II

The electrical parameters of Isofoton IS-80-12.

\begin{tabular}{c|c}
\hline \hline Parameter & Value \\
\hline Open-circuit voltage $V_{\mathrm{oc}}$ & $21.6 \mathrm{~V}$ \\
\hline Short circuit current $I_{\mathrm{sc}}$ & $4.98 \mathrm{~A}$ \\
\hline Voltage at MPP $V_{\mathrm{mp}}$ & $17.4 \mathrm{~V}$ \\
\hline Current at MPP $I_{\mathrm{mp}}$ & $4.60 \mathrm{~A}$ \\
\hline Maximum power $P_{\max }$ & $80 \mathrm{~W}$ \\
\hline Number of cells $N_{\mathrm{s}}$ & 36 \\
\hline Fill factor FF & $74 \%$
\end{tabular}

To calculate the characteristic $I-V$, we have used the model of Rauschenbusch [3]. The model only uses $I_{\mathrm{sc}}$, $V_{\text {oc }}$, and $P_{\max }$. The current-voltage characteristic is calculated by Eq. (1).

$$
I=I_{\mathrm{sc}}\left[1-C_{1} \exp \left(\frac{V}{C_{2} V_{\mathrm{oc}}}-1\right)\right],
$$

where the coefficients $C_{1}$ and $C_{2}$ are given by the following expressions [7].

$$
\begin{aligned}
& C_{1}=\left(1-\frac{I_{\mathrm{max}}}{I_{\mathrm{sc}}}\right) \exp \left(\frac{V_{\mathrm{max}}}{C_{2} V_{\mathrm{oc}}}\right), \\
& C_{2}=-\left(\frac{V_{\mathrm{max}}}{V_{\mathrm{oc}}}-1\right) / \ln \left(1-\frac{I_{\mathrm{max}}}{I_{\mathrm{sc}}}\right),
\end{aligned}
$$

where $I_{\max }$ and $V_{\max }$ are the current and the voltage at maximum power $P_{\max }$, while the short-circuit current $I_{\mathrm{sc}}$ can be simply calculated using Eq. (3) [9].

$$
I_{\mathrm{sc}}=I_{\mathrm{sc} 0}\left(\frac{G}{G_{0}}\right)^{a},
$$

where $I_{\mathrm{sc}}$ is the short-circuit current of the PV module, $I_{\mathrm{sc} 0}$ is the short-circuit current of the PV module under the standard test conditions STC, $G_{0}$ is the constant solar irradiance of $1000 \mathrm{~W} / \mathrm{m}^{2}, G$ is the solar irradiance while $a$ is the exponent responsible for all non-linear effects.

The following logarithmic function was used to calculate the open-circuit voltage:

$$
V_{\mathrm{oc}}=\frac{V_{\mathrm{oc} 0}}{1+b \ln \left(\frac{G}{G_{0}}\right)}\left(\frac{T_{0}}{T}\right)^{\gamma},
$$

where $V_{\text {oc }}$ and $V_{\text {oc0 }}$ are the open-circuit voltage under $G$ and $G_{0}$, respectively, $b$ is a PV module technology specific related dimensionless coefficient used by Van Dyk et al., $\gamma$ is the exponent considering all the non-linear temperature-voltage effects, and $T$ and $T_{0}$ are the PV module temperatures under normal solar irradiance $G$ and standard solar irradiance $G_{0}$, respectively.

$$
\begin{aligned}
& P_{\mathrm{max}}=V_{\mathrm{oc}} I_{\mathrm{sc}}\left(1-C_{1} \exp \left(\frac{V}{C_{2} V_{\mathrm{oc}}}\right)-1\right) \mathrm{FF}, \\
& \mathrm{FF}=\frac{I_{\mathrm{mp}} V_{\mathrm{mp}}}{I_{\mathrm{sc}} V_{\mathrm{oc}}},
\end{aligned}
$$

where $I_{\mathrm{mp}}$ and $V_{\mathrm{mp}}$ are the maximum current and maximum voltage of the PV module.

\section{Degradation analysis methodology}

In this study, we use the degradation of PV modules tests of IEC 61215 qualification standard. These tests are used for all manufacturers of PV modules to control the modes of degradation. The qualification tests are standardized by the International Electrotechnical Commission (IEC). The tests used in this work were done in collaboration with the control laboratory of the CONDOR ELECTRONICS Factory [10]. The qualifying tests will be detailed in the next section.

\subsection{Electroluminescence test}

This is the first method used to detect the most significant degradation modes in PV modules. The PV modules produce electricity from sunlight, but one can also produce heat radiation by applying the voltage to module. The heat radiation generated by the module can be "photographed" with sensitive measuring instruments and thus can reveal all electrical weak points in the form of fine lines. The machine is connected to a computer in order to display results, as shown in the Fig. 1.

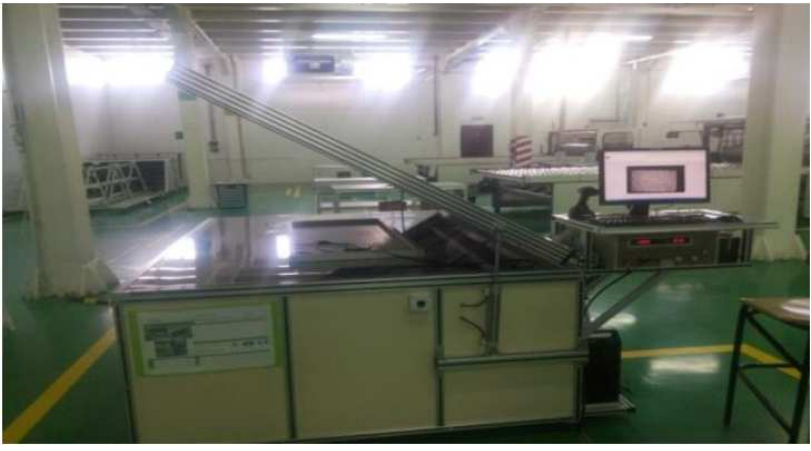

Fig. 1. The electroluminescence test machine.

\subsection{Humid environment leakage current test}

The purpose of this test is to evaluate the isolation of the module, operating in wet conditions and to check whether moisture resulting from rain, fog, dew or melted snow enters the active parts of the module circuitry, where it could cause corrosion, a ground fault or a security risk. The test consists of immersing the module into a tank filled with the required solution, to a depth 
sufficient to cover all surfaces except for the entries in the junction box (which are not designed to be submerged). The cable entries must be completely protected against water. The module output connections are set in short circuit to the positive pole of the testing equipment and the liquid test solution to the negative pole of the test equipment with a suitable metallic conductor. The voltage delivered by the test equipment is increased to $500 \mathrm{~V}$ or the maximum voltage of the system for the module, taking one of the two values, whichever is the highest [10]. The voltage is maintained at this value for 2 min, as shown in Fig. 2. The insulation resistance is measured. The results of this test are indicated by either "Pass" or "Fault".
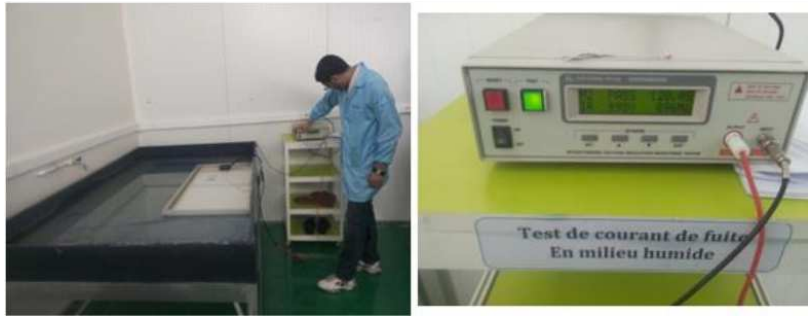

Fig. 2. The humid environment leakage current test.

\subsection{Grounding continuity test}

This test is only required if the module contains exposed conductive parts such as an aluminum, or a metallic junction box. This test is meant to verify whether the exposed conductive surfaces of the module are grounded properly in a PV system, as shown in Fig. 3.

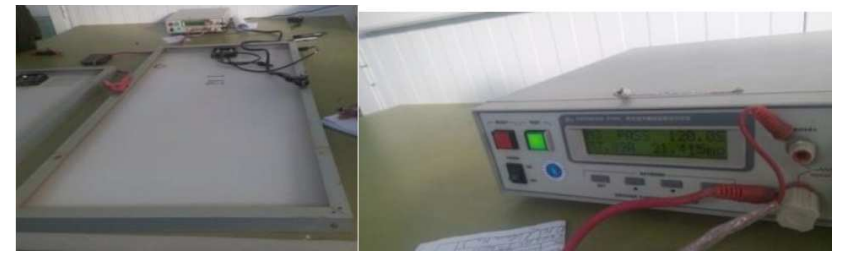

Fig. 3. The grounding continuity test.

\subsection{The Sun simulator test}

The Sun simulator is intended for testing solar modules. It uses the power simulator with flash light, in order to give the $I-V$ and $P-V$ characteristics under the STC test, for each panel. The test consists of two steps. The first step is to calibrate the machine parameters (Insertion STC Manufacturer parameters $V_{\mathrm{oc}}, I_{\mathrm{sc}}, V_{\mathrm{mp}}, I_{\mathrm{mp}}$, FF and $N_{\mathrm{s}}$ ). In the second step the conformity of the $I-V$ and $P-V$ curves with parameters of the nameplate is verified. The purpose of the test is to analyze the changes and examine the percentages of degradations, as shown in Fig. 4.

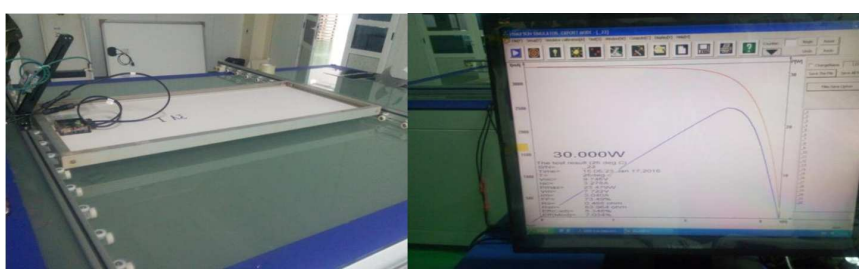

Fig. 4. The Sun simulator machine.

Figure 5 shows how the parameters of the PV module are determined using PVsyst 6.6.2 computer tool. Module behavior according to incident irradiation is illustrated in Fig. 6.

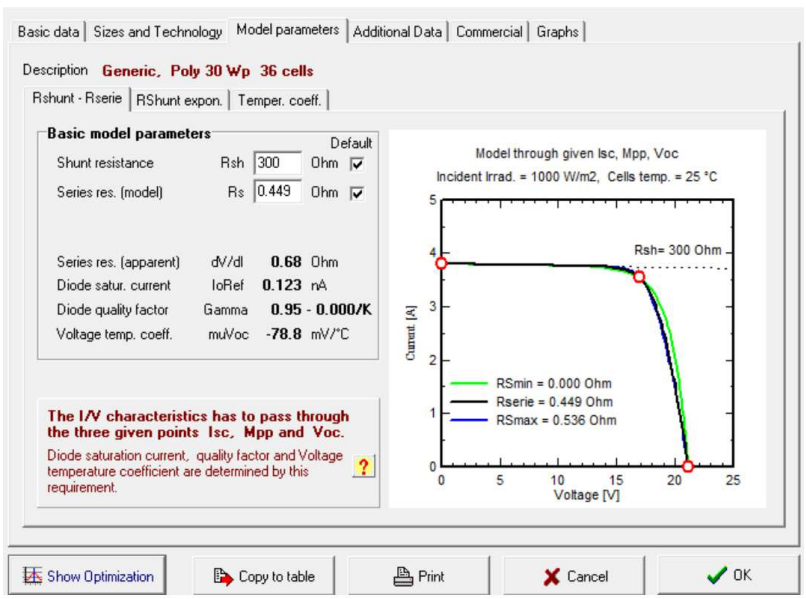

Fig. 5. Determination of PV module parameters and the $I-V$ characteristics.

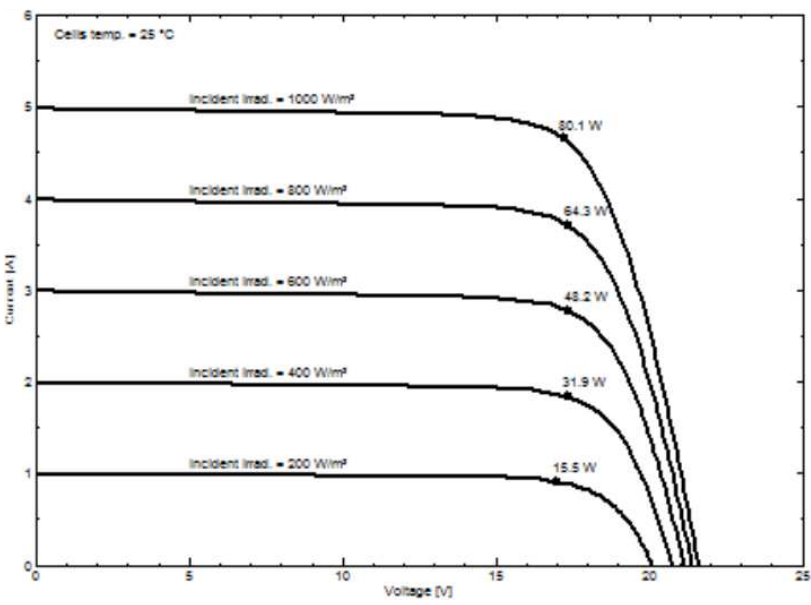

Fig. 6. Characteristic of PV module at various incident irradiation conditions.

\subsection{Degradation rate}

Each electric parameter, namely $I_{\mathrm{sc}}, V_{\mathrm{oc}}, P_{\max }, \mathrm{FF}$ has a degradation rate. The parameters' degradation rate is given by Eq. (7) [11, 12], 


$$
\mathrm{RD}(X) \%=\left(1-\frac{X}{X_{0}}\right) \times 100,
$$

where $X=\left[I_{\mathrm{sc}}, V_{\mathrm{oc}}, P_{\max }, \mathrm{FF}\right]$ represents the values after degradation, and $X_{0}=\left[I_{\mathrm{sc} 0}, V_{\mathrm{oc} 0}, P_{\max 0}, \mathrm{FF}_{0}\right]$ represents the reference values in standard test conditions (STC) given by the manufacturer. The yearly degradation rate is given by the Eq. (8),

$$
\operatorname{RDt}(X) \%=\left(\frac{\operatorname{RD}(X) \%}{\Delta t}\right) \times 100,
$$

where $\Delta t$ (years) is the exposure duration in the field of the PV modules, starting from commencement of operation until the end of the test.

\section{Experimental results and discussion}

The objective of this work is to evaluate the reliability, performance, and overall degradation of two crystalline silicon (c-Si) photovoltaic modules, functioning over a period of 12 years. The modules were operating in the steppe climatic conditions of Wilaya of Tiaret, in the west of Algeria, located between $34^{\circ} 55^{\prime} 0^{\prime \prime} \mathrm{N}$ and $1^{\circ} 34^{\prime} 60^{\prime \prime} \mathrm{E}$. The location is characterized by high potential of solar radiation $6502 \mathrm{~W} / \mathrm{m}^{2}$ annually, hot ambient temperature in summer rising up to $44^{\circ} \mathrm{C}$, and low temperature during winter, dropping to $-10^{\circ} \mathrm{C}$ and a dry climate with low humidity. The two modules under previous tests and the test results themselves are illustrated in Table III.

TABLE III

Visual inspection of the degradation modes results.

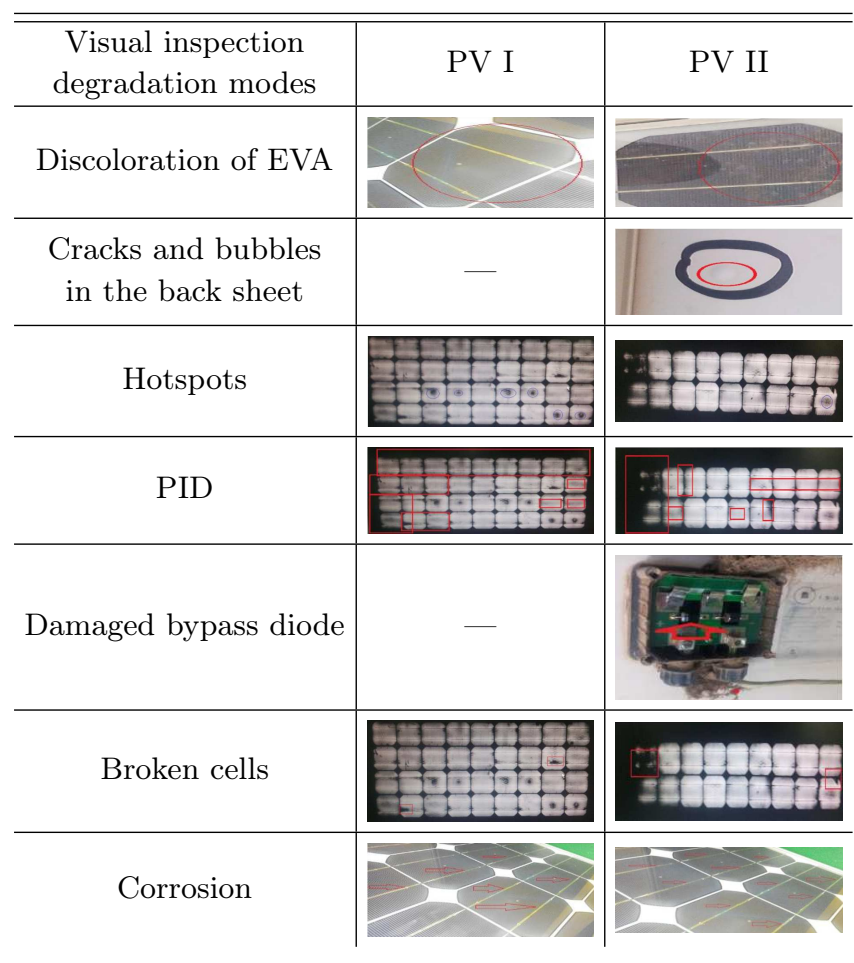

According to the results obtained, each degradation mode has a relationship with other modes of degradation.
The EVA was delaminating and changed its color to yellow and to brown in both modules at the same time, due to the photo-oxidation under high temperature and humidity [5]. This degradation of EVA increases the leakage current of the module, which is the main cause of the potential induced degradation (PID) in the two modules. On the other hand, the failure of bypass diodes of each module in the presence of partial shade, causes a hotspot problem.

The hot-spot is a physical phenomenon appearing when one of panel strings is shaded. It can then act then as an electric load [10]. However, if there is damage to either of the bypass diodes in the PV module II, the non-appearance of the column of the cell in series string under the EL test is caused by $I_{\mathrm{S}}$ open circuit. The high temperature $\left(44^{\circ} \mathrm{C}\right)$ at the module installation site and the exposure to UV radiation cause a change in the chemical structure of the back sheet, which led to the emergence of cracks and bubbles in the back sheet of the module PV II. The pressure caused by the bubbles was one of the reasons for the breaking of some cells.

The results of the humid environment leakage current test showed the existence of leakage current in the two photovoltaic modules. The reason for this is the damage of the glue, allowing for the entry of water into the depth of the module/the junction box. In addition to degradation of EVA, this problem increases the leakage current as we have pointed out earlier. The presence of the leakage current results in a difference of potential between cells. All these factors could cause the corrosion, the PID, the hot spot, and a security risk. On the other hand, the grounding continuity test gives an acceptable result for the two modules, which shows that the aluminum used in the photovoltaic support is of good quality.
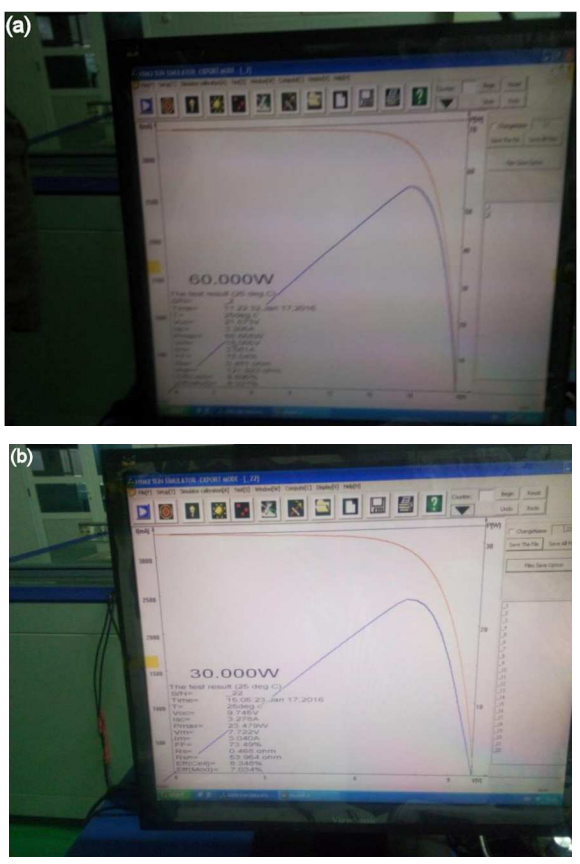

Fig. 7. (a) The $I-V$ for the PV I, (b) $P-V$ characteristics for the PV II. 
TABLE IV

Parameter values $V_{\mathrm{oc}}, I_{\mathrm{sc}}, V_{\mathrm{mp}}, I_{\mathrm{mp}}$ and $\mathrm{FF}$ after test.

\begin{tabular}{c|c|c|c}
\hline \hline Parameters & $\begin{array}{c}\text { Datasheet } \\
\text { value }\end{array}$ & $\begin{array}{c}\text { PV I } \\
\text { values }\end{array}$ & $\begin{array}{c}\text { PV II } \\
\text { values }\end{array}$ \\
\hline Open-circuit voltage $V_{\mathrm{oc}}[\mathrm{V}]$ & 21.6 & 21.57 & 10.53 \\
Short circuit current $I_{\mathrm{sc}}[\mathrm{A}]$ & 4.98 & 3.306 & 3.278 \\
Voltage at MPP $V_{\mathrm{mp}}[\mathrm{V}]$ & 17.4 & 18.065 & 8.565 \\
Current at MPP $I_{\mathrm{mp}}[\mathrm{A}]$ & 4.60 & 3.81 & 3.048 \\
Maximum power $P_{\max }[\mathrm{W}]$ & 80 & 60 & 30 \\
Fill factor FF [\%] & 74 & 63 & 24
\end{tabular}

In order to examine the performance and lifetime of the degraded PV modules, which depend mainly on the electrical results obtained for $I-V$ and $P-V$ characteristic curves, the Sun simulator test was used to find different results for the two examined modules. Figure $7 \mathrm{a}$ and $\mathrm{b}$ shows the $I-V$ and $P-V$ characteristic curves for the PV I and PV II, respectively. The parameters $V_{\mathrm{oc}}, I_{\mathrm{sc}}$, $V_{\mathrm{mp}}, I_{\mathrm{mp}}$, and FF, determined after testing, are shown in Table IV. The degradation rate of each parameter is presented in Table V.

TABLE V

Degradation factors of tested modules.

\begin{tabular}{|c|c|c|c|c|c|c|c|c|c|c|c|c|}
\hline \multirow[t]{3}{*}{ Parameters } & \multicolumn{6}{|c|}{ Parameter degradation rate } & \multicolumn{6}{|c|}{ Yearly degradation rate } \\
\hline & \multicolumn{6}{|c|}{ RD } & \multicolumn{6}{|c|}{ RDt } \\
\hline & $V_{\mathrm{oc}}[\%]$ & $I_{\mathrm{sc}}[\%]$ & $I_{\mathrm{mp}}[\%]$ & $V_{\mathrm{mp}}[\%]$ & $P_{\max }[\%]$ & FF [\%] & $V_{\mathrm{oc}}[\%]$ & $I_{\mathrm{sc}}[\%]$ & $I_{\mathrm{mp}}[\%]$ & $V_{\mathrm{mp}}[\%]$ & $P_{\max }[\%]$ & $\mathrm{FF}[\%]$ \\
\hline PV I & 0.13 & 33 & 17.17 & -3.82 & 25 & 14 & 0.01 & 2.75 & 1.43 & 0.31 & 2.08 & 1.16 \\
\hline PV II & 51 & 34.17 & 33.73 & 50.77 & 62.5 & 67.56 & 4.25 & 2.84 & 2.81 & 4.23 & 5.2 & 5.63 \\
\hline
\end{tabular}

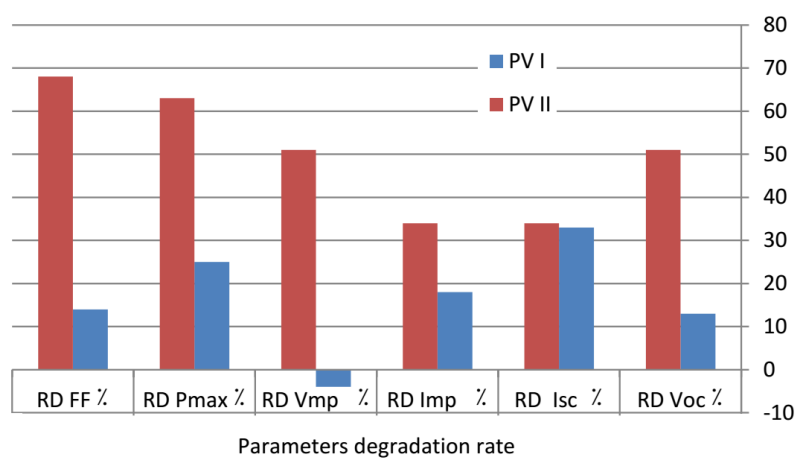

Fig. 8. Comparison of degradation rate parameters $\left(I_{\mathrm{sc}}, V_{\mathrm{oc}}, P_{\max }\right.$ and $\left.\mathrm{FF}\right)$ for two PV modules after 12 years of operation.

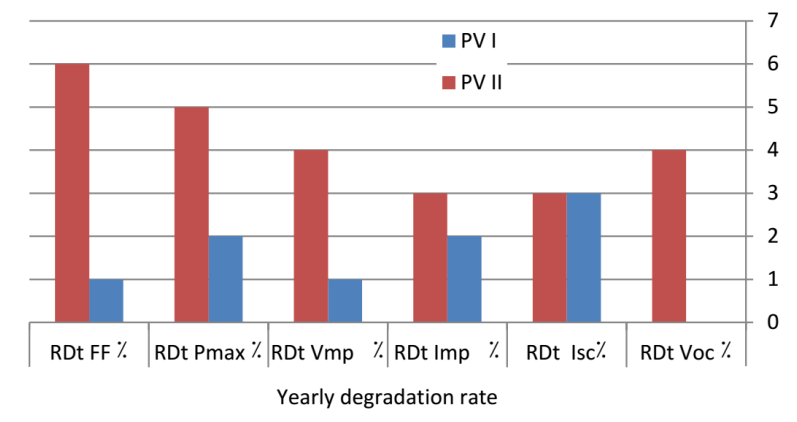

Fig. 9. Comparison of yearly degradation rate of parameters $\left(I_{\mathrm{sc}}, V_{\mathrm{oc}}, P_{\max }\right.$ and $\left.\mathrm{FF}\right)$ for two $\mathrm{PV}$ modules after 12 years of operating.

Figures 8 and 9 clearly show that $P_{\max }$ and FF are affected by the modes of degradation. Figure 6 shows that the percentage $\mathrm{RD} V_{\mathrm{mp}}(\%)$ is negative, evidencing an increase of $V_{\text {oc }}$ as compared to the datasheet value of $V_{\text {oc }}$. This is due to the existence of hot spots under the influence of partial shading, which leads to an increase in the electrical resistance, causing a rise in open-circuit voltage $V_{\mathrm{oc}}$.

\section{Conclusions}

The main objective of this article is to examine the impact of climatic conditions on the solar panels' performance and lifetime in the steppe environment, this being a region where temperatures rise or drop suddenly. The performance degradation of PV modules after 12 years of operation was presented.

The visual inspection and the observed electrical characteristics have revealed that the PID is the largest issue with the appearance or performance of PV modules, because it generates a host of problems, including discoloration of the encapsulant materials, cracks and bubbles in the back sheet, and degradation of the glass surface. Another issue is the presence of hotspots, potentially causing partial shading and/or corrosion of cells.

Experimental results show that the loss of maximum power in the two modules, PV I and PV II, under the influence of different modes of yearly degradation is ranging from $2.08 \%$ to $5.2 \%$. This demonstrates the effect of steppe weather conditions on the PV module during exposure time.

\section{Acknowledgments}

The authors are grateful to the control laboratory of CONDOR ELECTRONICS Factory for support in experiments. 


\section{References}

[1] B. Kiris, O. Bingol, R. Senol, A. Altintas, Acta Phys. Pol. A 130, 55 (2016).

[2] Z. Er, I.B. Turna, Acta Phys. Pol. A 129, 865 (2016).

[3] F. Bandou, A.H. Arab, M.S. Belkaid, A. Charki, Int. J. Hydrogen Energy 40, 13839 (2015).

[4] M. Vasquez, I. Ray-Stolle, Prog. Photovolt.: Res. Appl. 16, 419 (2008).

[5] A. Ndiaye, C.M.F. Kébé, A. Charki, P.A. Ndiayea, V. Sambou, A. Kobi, Solar Energy 103, 70 (2014).

[6] A. Ricaud, Solar photovoltaic cells, French Polytechnic and University Presses, 1997, p. 313.
[7] N.C. Bezir, I. Akkurt, N. Ozek, Energy Sources A 32, $512(2010)$.

[8] N.C. Bezir, I. Akkurt, N. Ozek, Energy Sources A 32, 995 (2010).

[9] A. Ndiaye, C.M.F. Kébé, P.A. Ndiaye, A. Charki, A. Kobi, V. Sambou, Energy Procedia 36, 1222 (2013).

[10] www.condor.dz/fr/les-panneaux-solaires.

[11] T. Sample, Failure modes observed in real use and long term exposure, in: PV Reliability, Workshop, Berlin 2011.

[12] M. Saadsaoud, Int. J. Renew. Energy Res. (IJRER) 6, 413 (2016) 